Article

\title{
Application of Adaptive Tuned Magneto-Rheological Elastomer for Vibration Reduction of a Plate by a Variable-Unbalance Excitation
}

\author{
Un-Chang Jeong \\ Department of Automotive Engineering, Honam University, Gwangsan-gu, Gwangju 62399, Korea; \\ ucjeong@honam.ac.kr
}

Received: 12 May 2020; Accepted: 3 June 2020; Published: 5 June 2020

\begin{abstract}
The present study on vibration reduction in systems wherein the excitation frequency is variable designed and fabricated a magnetorheological elastomer (MRE)-based tunable dynamic vibration absorber and evaluated its performance in an experimental manner. The design of an MRE-based adaptive tuned dynamic vibration absorber (ATDVA) involves designing two parts: stiffness and mass. Before designing the MRE-based ATDVA, this study determined the resonance frequency of a target object for vibration reduction. For the design of the ATDVA's stiffness part, the thickness of specimens was determined by measuring the rate of variation of the MRE's shear modulus with respect to the MRE's thickness. The design of the mass part was optimized using sensitivity analysis and genetic algorithms after the derivation of formulas for its magnetic field and mass. Further, upon the application of an electric current to the MRE, its stiffness was measured so that the stiffness of the designed MRE-based ATDVA could be tuned accordingly. Finally, the vibrationreducing performance of the MRE-based ATDVA was evaluated to determine the applicability of the vibration absorber under the condition of variable-frequency excitation.
\end{abstract}

Keywords: variable-frequency excitation; magnetorheological elastomer (MRE); genetic algorithm; MRE-based adaptive tuned dynamic vibration absorber (MRE-based ATDVA)

\section{Introduction}

The motors that are used in our lives serve their intended purposes of use with the number of revolutions per minute (rpm) adjusted to users' needs. Such RPM adjustments act as the variable-frequency excitation of mechanical systems. Vibrations generated by variable-frequency excitation can cause resonance of mechanical systems. A common way to prevent such failure or damage due to resonance is to use a dynamic vibration absorber. The dynamic vibration absorber is attached to a mechanical system to absorb or dampen vibrations at designed frequencies. It is widely known as a technology for forced reduction of vibrations and can inhibit vibrations very effectively where the vibration frequency remains constant. Moreover, it is easily applicable to existing systems without major alterations to their structures [1-3]. For that reason, until recently, the dynamic vibration absorber has been reported to have a wide variety of applications [4-6]. However, the vibration-reducing performance of a dynamic vibration absorber deteriorates if the excitation frequency is variable. Installing multiple dynamic vibration absorbers has been proposed as a solution to the resonance problem $[7,8]$. Among others, Seto et al. proposed a dual dynamic vibration absorber [7]. A typical way to build a system with multiple dynamic vibration absorbers is to attach several single-degree-of-freedom (SDOF) dynamic vibration absorbers. The multiple-dynamic-vibration-absorber system is designed by optimizing the stiffness and damping ratio of each SDOF dynamic vibration absorber such that a vibration reduction is achieved in a targeted frequency range. However, such a multiple-dynamic-vibration-absorber 
system is difficult to install because of its large bulk. Another problem is that a resonance frequency is generated between two adjacent frequencies designed for vibration reduction performance. In an attempt to overcome this problem, Seto et al. adjusted the damping ratio to reduce the resonance of newly generated frequencies. Nevertheless, the vibration reduction performance deteriorated at existing target frequencies. Therefore, reducing vibrations caused by variable-frequency excitation requires a tunable dynamic vibration absorber, which helps reduce vibrations depending on the new variable frequency. The idea of the tunable dynamic vibration absorber is that the vibration absorber's natural frequency varies to correspond with the variable excitation frequency. Any variation in the natural frequency of the tunable dynamic vibration absorber occurs as a result of a change in its mass or stiffness. However, the mass of the dynamic vibration absorber is unlikely to vary every moment, so changes should be made in stiffness. To this end, research has been carried out on momentary changes in stiffness that can lead to variations in the natural frequency of a tunable dynamic vibration absorber and on how to control such changes [9]. Studies of stiffness-variable dynamic vibration absorbers are conducted mainly with shape-memory alloys [10-19]. A problem with stiffness-variable dynamic vibration absorbers using shape-memory alloys is that their response rates should be improved.

An MRE-based dynamic vibration absorber has been recently proposed to solve that problem [20]. Magnetorheological elastomers (MREs) are a class of smart materials whose mechanical properties vary due to an externally applied magnetic field with magnetic reactive particles (MRPs) mixed in a rubber matrix [20-26]. Elastomers such as natural rubber (NR) and silicone are commonly used as matrices, and when a magnetic field is externally applied, their shear modulus is varied by a force of electromagnetic attraction between MRPs. X.L. Gong et al. [27-42] presented a concept of the MRE-based dynamic vibration absorber based on the mechanism of shear modulus variation with the applied magnetic field. In this paper, however, we merely suggested the applicability of an MRE-based dynamic vibration absorber without evaluating its design and performance. For designing the MRE-based tunable dynamic vibration absorber, a target frequency for vibration reduction should be set, and the physical properties of the MRE should be evaluated. In particular, the MRE's shear modulus must be measured for use as the stiffness of the dynamic vibration absorber. A typical example of research on shear modulus measurements of MREs is a study by Yoon et al. [21,22]. They evaluated the shear modulus of MREs with respect to MRPs and an applied electric current but not the rate of variation of shear modulus with the thickness of MREs. For that reason, it is necessary to evaluate how the MREs' shear modulus varies with the thickness of specimens and design an appropriate stiffness for the dynamic vibration absorber. In designing an MRE-based tunable dynamic vibration absorber, its mass is determined by a target frequency and the MRE's stiffness, and should also be optimized for maximum magnetic field. Recently, numerical and finite element analysis of magnetic-field application device for MRE was conducted by Li et al. [23]. However, further research is needed to be applied to ATDVA.

A genetic algorithm that provides a means of finding optimal solutions was used as a way to optimize the design of the magnetic field. The genetic algorithm applies natural evolution and natural genetics to design optimization and uses a number of individuals simultaneously to find an optimal solution through multiple search paths. It reaches a final optimal solution by handing down the current individuals' good traits to the individuals of the next generation $[43,44]$. Regarding the mass part of an MRE-based dynamic vibration absorber, the genetic algorithm should find globally optimal solutions for different design parameters. The coil's number of turns and radius are required for application of a magnetic field to the MRE-based ATDVA. The number of coil turns refers to the number of coil windings and is thus expressed as an integer, and the value of the radius should be set in compliance with the fabrication regulations. Therefore, an optimization technique (i.e., genetic algorithms) should be performed although the design parameters of the coil's number of turns and radius are difficult to apply to a numerical optimization formula because they are discontinuous functions that are not differentiable. It is therefore necessary to theoretically model the magnetic-field application device 
and the mass part of the MRE-based dynamic vibration absorber, and a sensitivity analysis should be conducted to find and select appropriate design parameters. A genetic algorithm must then find an optimal solution with the selected design parameters.

The designed MRE-based dynamic vibration absorber allows the stiffness to vary and works to reduce vibrations in systems wherein the excitation frequency is variable. Thus, when an electric current is applied, there is a need to identify the stiffness of the MRE-based ATDVA. Further, there is also a need to identify how the applied electric current is related to the MRE-based ATDVA's vibration reduction frequency. Finally, for vibration reduction in those systems wherein the excitation frequency is variable, it is necessary to determine the vibration-reducing performance of the MRE-based ATDVA.

This work evaluates the vibration-reducing performance of an MRE-based tunable dynamic vibration absorber for reducing the vibration of systems wherein the excitation frequency is variable. To this end, the vibration-reducing performance of the ATDVA is simulated for its applicability under the condition of variable-frequency excitation. For designing the MRE-based ATDVA, this study determines the natural frequencies of a plane plate targeted for vibration reduction. The MRE's shear modulus is evaluated in designing the stiffness part of the MRE-based ATDVA. In designing the vibration absorber's mass part, the mass and magnetic field are theoretically formulated, and design optimization is performed using a sensitivity analysis and genetic algorithm. In addition, for the adaptive control of the MRE-based ATDVA, its stiffness is identified when an electric current is applied. Finally, the vibration-reducing performance of the MRE-based ATDVA is evaluated under the condition of variable-frequency excitation.

\section{Numerical Analysis of the ATDVA's Vibration-Reducing Performance for a Plate Receiving Variable Inputs}

\subsection{Frequency Characterization of the Plate and Modeling for Numerical Analysis}

The frequency characteristics of the plate should be identified before the design of the MRE-based ATDVA. Figure 1 shows the plate fabricated for that purpose. Figure 2 illustrates the experimental setup for measuring the natural frequencies of the plate. For the measurement of natural frequencies, an accelerometer (Endevco 65-100-X) was installed in the center, and an exciter (B\&K shaker 4810) was placed in the center as well. A transfer function was obtained using the installed accelerometer and exciter and measured using an FFT analyzer (B\&K Pulse 3560-B-040).

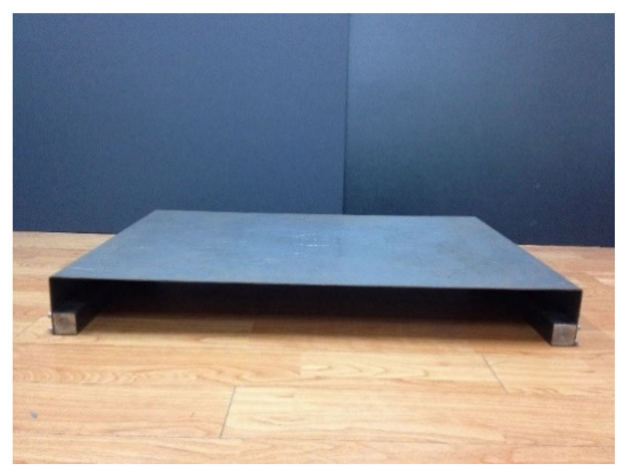

Figure 1. Target structure.

The transfer function measurements revealed that the plate had natural frequencies of $10 \mathrm{~Hz}, 57 \mathrm{~Hz}$ and $122 \mathrm{~Hz}$ (Figure 3). A frequency range of $110-130 \mathrm{~Hz}$ near the $122 \mathrm{~Hz}$ natural frequency wherein the transfer function had a high magnitude was selected as the target range for vibration reduction.

For a numerical analysis of the dynamic vibration absorber, the plate was modeled as a simple SDOF system for resonance to occur at the target frequency of $122 \mathrm{~Hz}$ for vibration reduction. The system was designed to have a mass of $12 \mathrm{~kg}$ similar to that of the plate and a stiffness of approximately $705,000 \mathrm{~N} / \mathrm{m}$. 


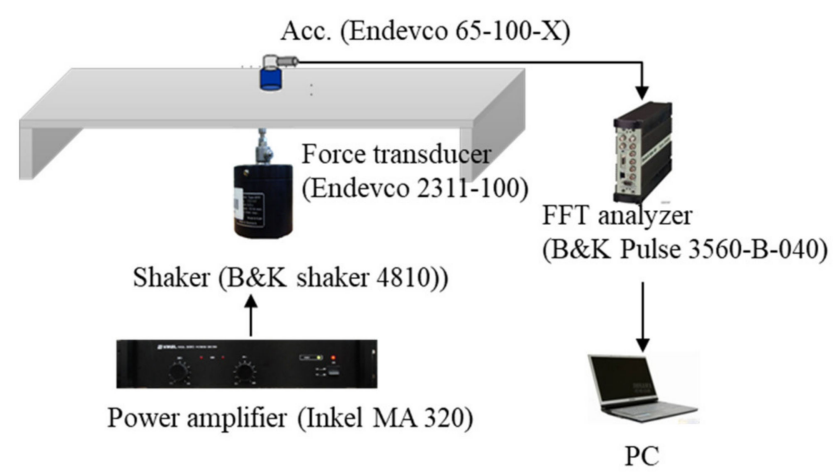

Figure 2. Experimental setup for modal test.

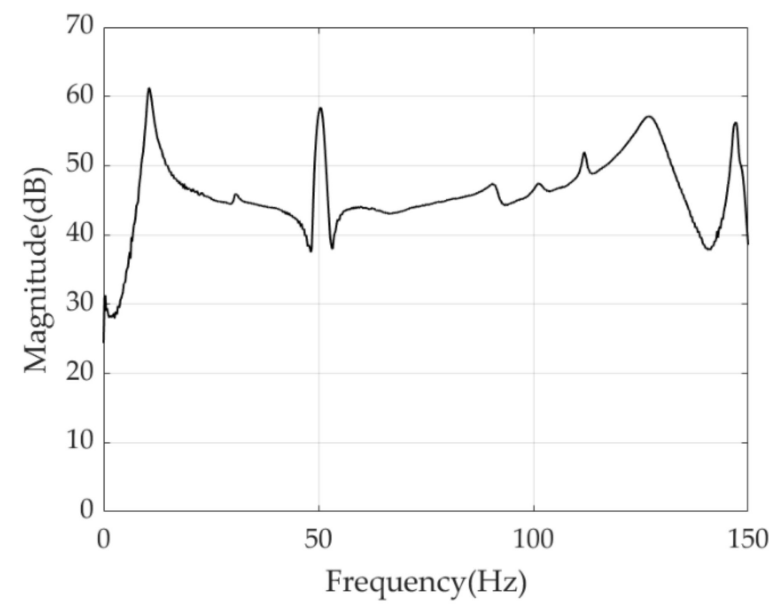

Figure 3. Frequency response function of the target system.

The variable input can be defined by Equation (1):

$$
F(t)=\sin (2 \pi \omega t)
$$

where $\omega=a t, a$ is a sweep rate which is defined as a frequency variation per unit time.

The numerical analysis is conducted with $a=10$. A fourth-order Runge-Kutta scheme was used in the numerical analysis.

\subsection{SDOF and Dual Dynamic Vibration Absorbers}

Figure 4 shows an SDOF dynamic vibration absorber and the system (target structure) for which vibration reduction was sought. The target structure is connected to the ground by stiffness, and the mass and stiffness on it constitute the SDOF dynamic vibration absorber. In the case of variable-frequency excitation, the equations of motion of the SDOF dynamic vibration absorber and the target system for vibration reduction are expressed by Equations (2) and (3), respectively.

$$
\begin{aligned}
m \ddot{x}+k x+k_{a}\left(x-x_{a}\right) & =F(t) \\
m_{a} \ddot{x}_{a}+k_{a}\left(x_{a}-x\right) & =0
\end{aligned}
$$

Danial J. Inman proposed that the mass ratio $\mu$ between the target structure and the SDOF dynamic vibration absorber should be designed to be $0.05 \leq \mu=m_{a} / m \leq 0.25$ [2]. Further, he suggested that the mass ratio should be set to $\mu=0.25$ for vibration reduction in wider frequency ranges. In this section, therefore, a simulation of vibration reduction by the SDOF dynamic vibration absorber was carried out with a mass ratio of $\mu=0.25$. The target frequency selected for vibration reduction was $20 \mathrm{~Hz}$. 
The simulation numerically computed the acceleration and frequency responses from the target object for vibration reduction (Figure 5).

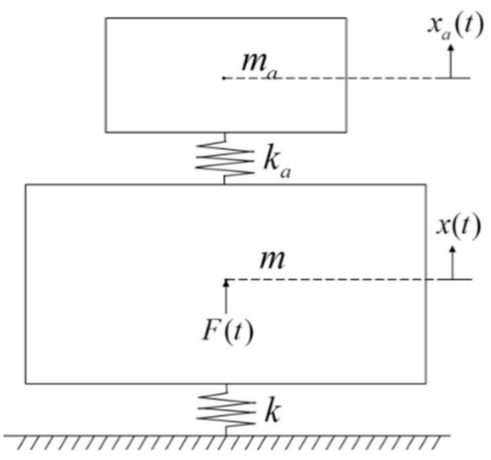

Figure 4. Modeling of single degrees of freedom vibration absorber and target structure.

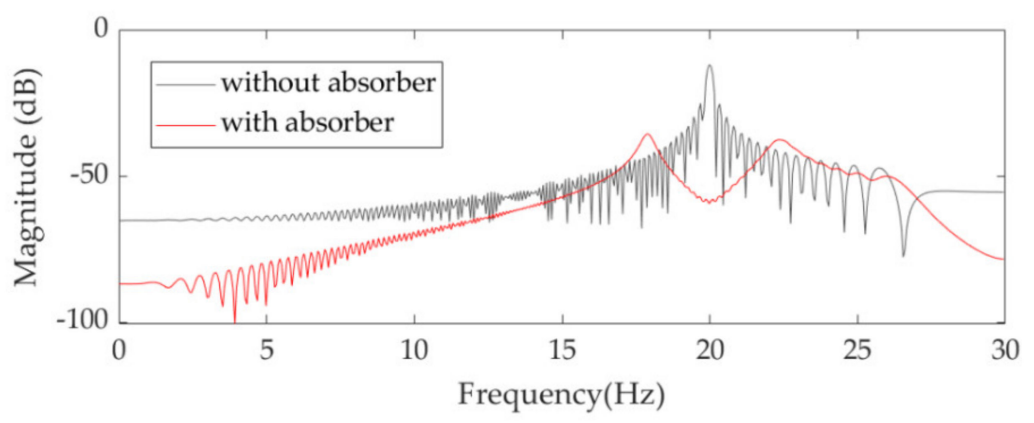

(a)

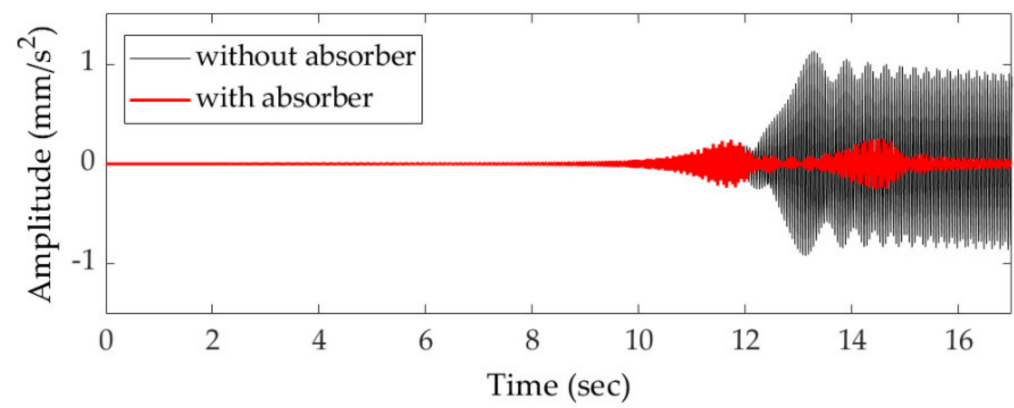

(b)

Figure 5. Numerical simulation results of single degrees of freedom vibration absorber. (a) Frequency response, (b) Time response (acceleration).

The simulation results revealed that the SDOF dynamic vibration absorber reduced vibrations at the target frequency during variable-frequency excitation but with two resonance frequencies occurring near the target frequency (Figure 5a). One method proposed as a solution to the resonance problem is to install a number of dynamic vibration absorbers $[7,8]$.

Figure 6 shows the dual dynamic vibration absorber and target system for vibration reduction, proposed by Seto et al. [7]. The target system for vibration reduction is connected to the ground by stiffness, and two masses on it constitute the dual dynamic vibration absorber. In the case of variable-frequency excitation, the equations of motion of the dual dynamic vibration absorber and target system are given by Equations (4)-(6).

$$
m \ddot{x}+k x+k_{1}\left(x-x_{1}\right)+k_{2}\left(x-x_{2}\right)=F(t)
$$




$$
\begin{aligned}
& m_{1} \ddot{x}_{1}+k_{1}\left(x_{1}-x\right)=0 \\
& m_{2} \ddot{x}_{2}+k_{2}\left(x_{2}-x\right)=0
\end{aligned}
$$

A numerical simulation of vibration reduction was performed using the dual dynamic vibration absorber's design factors-i.e., mass ratio and damping ratio as proposed by Seto et al., who used a mass ratio of 0.15 and damping ratios of 0.166 and 0.299 . A frequency range of $15-23 \mathrm{~Hz}$ was selected as the target range for vibration reduction. The simulation numerically computed the acceleration and frequency responses from the target object for vibration reduction.

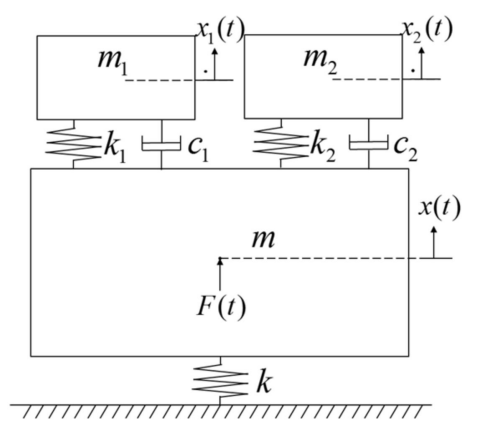

Figure 6. Modeling of dual dynamic absorber and target structure.

The simulation results revealed that the dual dynamic vibration absorber reduced vibrations at target frequencies during variable-frequency excitation. In addition, it was found to overcome the drawbacks of SDOF dynamic vibration absorbers without producing two resonance frequencies outside the target frequency range. However, high damping ratios caused a degradation of $20 \mathrm{~Hz}$ in vibration-reducing performance, compared to SDOF dynamic vibration absorbers (Figure 7).

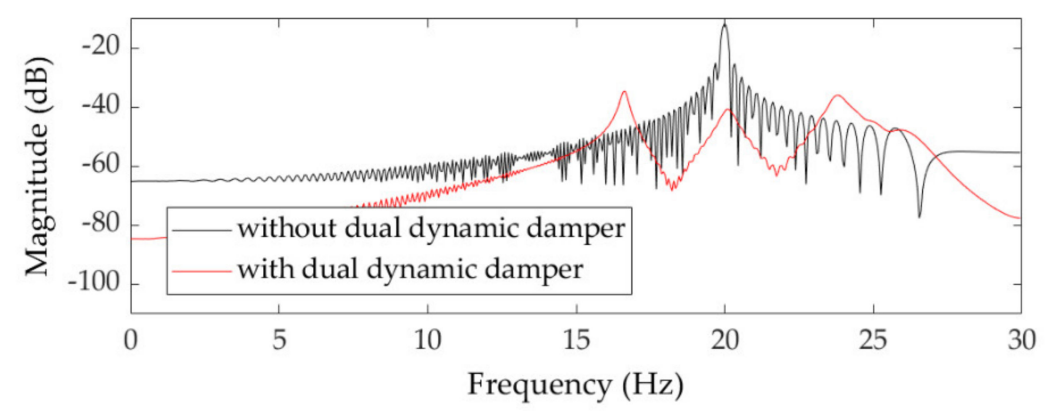

(a)

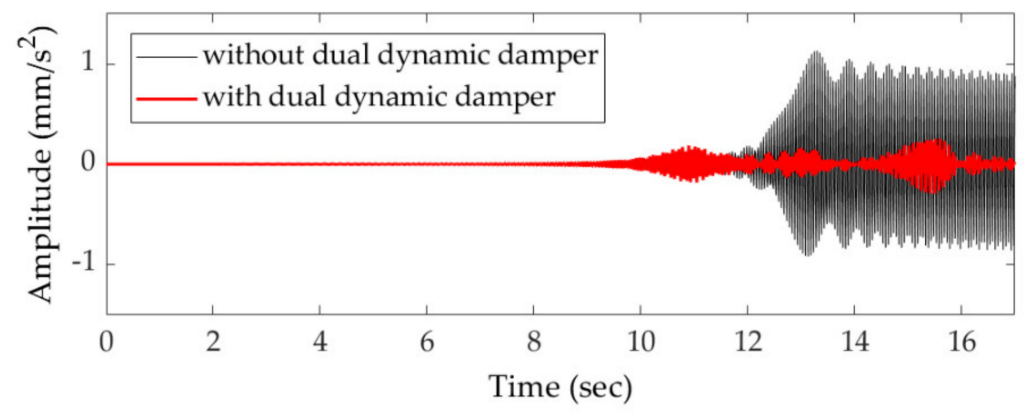

(b)

Figure 7. Numerical simulation results of dual dynamic absorber. (a) Frequency response, (b) Time response (acceleration). 


\subsection{Adaptive Tuned Dynamic Vibration Absorber (ATDVA)}

An adaptive tunable dynamic vibration absorber tunes its natural frequency by varying the stiffness depending on the variable excitation frequency coming into a target object for vibration reduction. Accordingly, the dynamic vibration absorber's vibration-reducing performance was evaluated by varying the stiffness correspondingly to the variable excitation frequency applied to the target object.

The target object for vibration reduction with the adaptive tunable dynamic vibration absorber on it was modeled as a two-degree-of-freedom system (Figure 8), which was formulated as shown in Equations (7) and (8).

$$
\begin{gathered}
m \ddot{x}+k x+k_{\text {mre }}\left(x-x_{\text {mre }}\right)=F(t) \\
m_{\text {mre }} \ddot{x}_{\text {mre }}+k_{\text {mre }}\left(x_{\text {mre }}-x\right)=0
\end{gathered}
$$

In this section, a simulation of vibration reduction by the ATDVA was conducted using a mass ratio of 0.15 . A frequency range of $15-23 \mathrm{~Hz}$ was selected as the target range for vibration reduction. The simulation numerically computed the acceleration and frequency responses from the target object for vibration reduction.

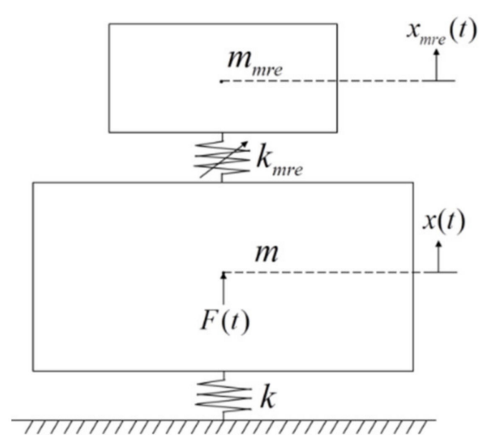

Figure 8. Modeling of adaptive tuned vibration absorber and primary structure.

The simulation results showed that the adaptive tunable dynamic vibration absorber reduced vibrations at target frequencies during variable-frequency excitation (Figure 9). It exhibited outstanding vibration-reducing performance at the target frequency by overcoming the drawbacks of SDOF and dual dynamic vibration absorbers. This indicates that it was effective for vibration reduction at target frequencies to install an SDOF dynamic vibration absorber for each frequency.

Three different types of dynamic vibration absorbers were compared for their vibration-reducing performance in terms of mean vibration reduction response in the target frequency range $(15-23 \mathrm{~Hz})$ (Table 1).

Table 1. Reduction of frequency responses due to vibration absorber type.

\begin{tabular}{cc}
\hline Type & Reduction of Frequency Response (15-23 Hz, Mean) \\
\hline SDOF absorber & $7 \mathrm{~dB}$ \\
Dual & $10 \mathrm{~dB}$ \\
ATDVA & $15.3 \mathrm{~dB}$ \\
\hline
\end{tabular}

From the comparison, it was found that the SDOF dynamic vibration absorber reduced vibrations at a designed frequency $(20 \mathrm{~Hz})$ but showed the poorest performance and that the best vibration-reducing performance was achieved by the adaptive tunable dynamic vibration absorber. 


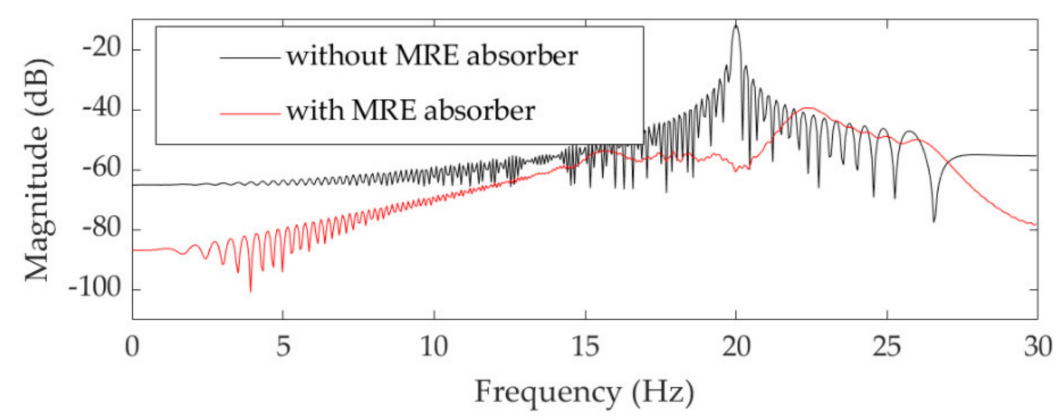

(a)

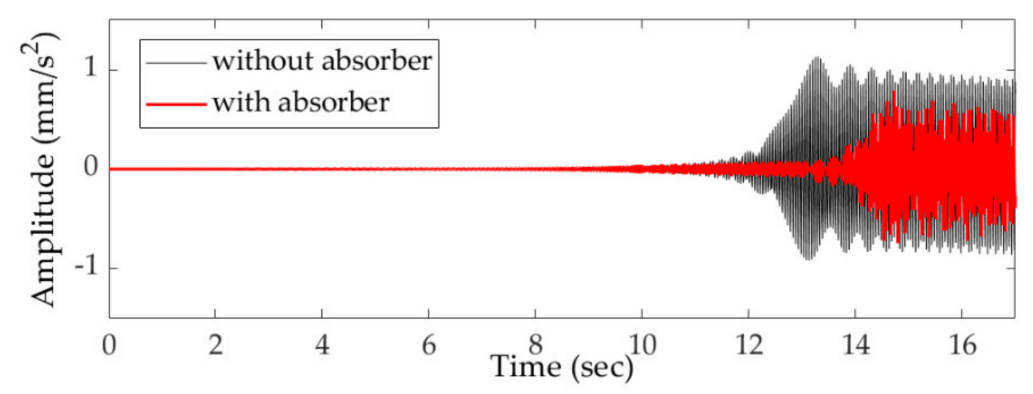

(b)

Figure 9. Numerical simulation results of adaptive tuned vibration absorber. (a) Frequency response, (b) Time response (acceleration).

\section{Sensitivity Analysis and Genetic Algorithms for Design Optimization of the MRE-Based ATDVA}

\subsection{Evaluation of Variations in Shear Modulus for MRE Design}

The MRE's shear stiffness was derived by measuring its shear modulus. The derived shear stiffness was used as the stiffness part of the MRE-based dynamic vibration absorber. The shear modulus was measured using the system presented by Yoon et al. [21].

The rate of variation of the MRE's shear stiffness was measured to design the stiffness part of the MRE-based ATDVA. The specimen of MRE was spherical in shape with a radius of $15 \mathrm{~mm}$, so there was no magnetic field leakage at the time of magnetic-field excitation. For easy fabrication, the MRE was prepared in thicknesses of $2 \mathrm{~mm}, 4 \mathrm{~mm}, 6 \mathrm{~mm}, 8 \mathrm{~mm}$ and $10 \mathrm{~mm}$, and the rate of variation of its shear modulus was measured for each thickness.

Natural rubber was used as the base matrix, which was prepared by mixing MRPs and additives. The volume ratio of MRPs was set to 40 vol. $\%$ at which the rate of variation of shear modulus was highest [21]. Additives necessary for MRE mixing are listed in Table 2.

Table 2. Composition of MRE materials.

\begin{tabular}{ccccc}
\hline Matrix & $\begin{array}{c}\mathrm{ZnO} \\
\text { (Activator) }\end{array}$ & $\begin{array}{c}\text { Stearic Acid } \\
\text { (Activator) }\end{array}$ & $\begin{array}{c}\mathrm{CZ} \\
\text { (Accelerator) }\end{array}$ & $\begin{array}{c}\text { Sulfur (Crosslink } \\
\text { agent) }\end{array}$ \\
\hline Natural Rubber & $5 \mathrm{phr}$ & $2 \mathrm{phr}$ & $0.8 \mathrm{phr}$ & $2.5 \mathrm{phr}$ \\
\hline
\end{tabular}

Isotropic and anisotropic MREs were prepared through the following process (Figure 10):

For fabrication of MREs, the natural rubber and different additives (Figure 10a) listed in Table 2 were mixed on a roll-mill. During the repeated mixing process on the roll-mill (Figure 10b), the primary compound of homogeneous MREs was prepared by mixing the natural rubber base matrix, MRPs and 
additives. For its molecular chain to relax, the prepared primary compound was stabilized for $24 \mathrm{~h}$ at room temperature.

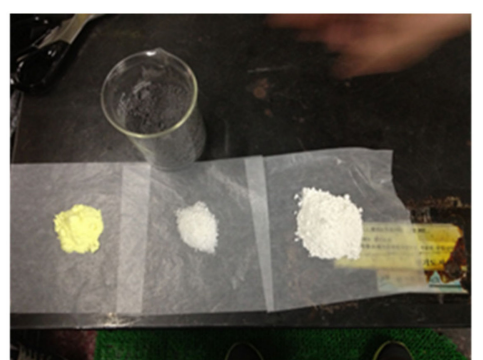

(a)

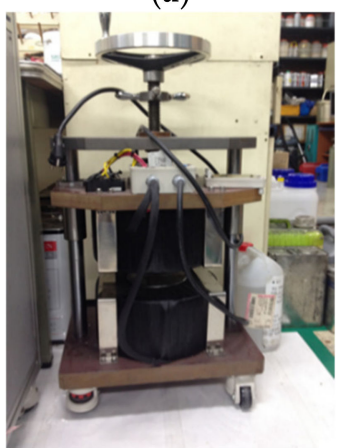

(c)

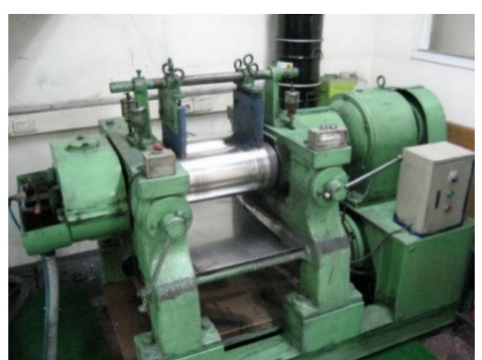

(b)

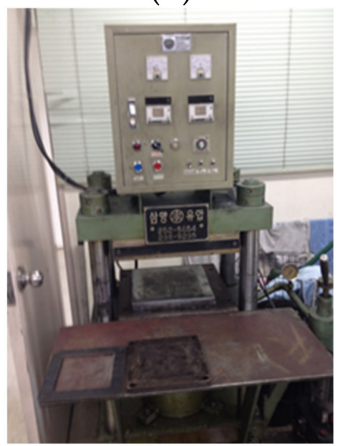

(d)

Figure 10. Process of MRE fabrication. (a) Composition of MRE materials, (b) roll-mill, (c) MRP Orientation, (d) Vulcanization.

After complete stabilization at room temperature, the isotropic MRE did not undergo any orientation process, and MRPs in the anisotropic MRE were oriented by application of a magnetic field (Figure 10c). Specimens were prepared by vulcanizing the MREs in a press for approximately $10 \mathrm{~min}$ under the conditions of $160^{\circ} \mathrm{C}$ and $2000 \mathrm{psi}(14.8 \mathrm{kPa})$ (Figure 10d).

The following is how the shear modulus of an MRE is measured:

The lower-middle part of a beam with both ends fixed is excited by $20-\mathrm{kHz}$ white noise with a shaker, and the exciting force is measured using a force transducer. The MRE is placed between a magnetic-field application device (magnetic-flux generator) and an oscillator so that it is movable in the shear direction. With a current of 0-3 A applied to the magnetic flux generator, the transfer function is measured through an accelerator and the exciting force.

The MRE's shear modulus is calculated by substituting the frequency of the measured transfer function's secondary eigenmode into Equation (9) as presented by Yoon et al.

$$
G_{m r e}=\frac{2 \pi^{2} f^{2} m h}{A}
$$

where $f$ denotes the frequency of the measured secondary eigenmode, $m$ is the mass of the oscillator, $h$ is the thickness of the specimen, and $A$ is the area of the specimen.

The rate of variation of the prepared MRE's shear modulus was measured as follows (Figure 11):

The rate of variation of shear modulus was greater in the anisotropic MRE than in the isotropic MRE and when their thickness was smaller. The anisotropic MRE is thought to offer greater resistance in the shear direction when a magnetic field is applied with MRPs clustered. During the fabrication of MREs, as their thickness increases, the magnetic field becomes more unlikely to pass through the MREs, so clusters are not formed properly.

Therefore, the stiffness part of the MRE-based ATDVA must be anisotropically oriented with a thickness of $2 \mathrm{~mm}$ for a large rate of variation of shear modulus. 


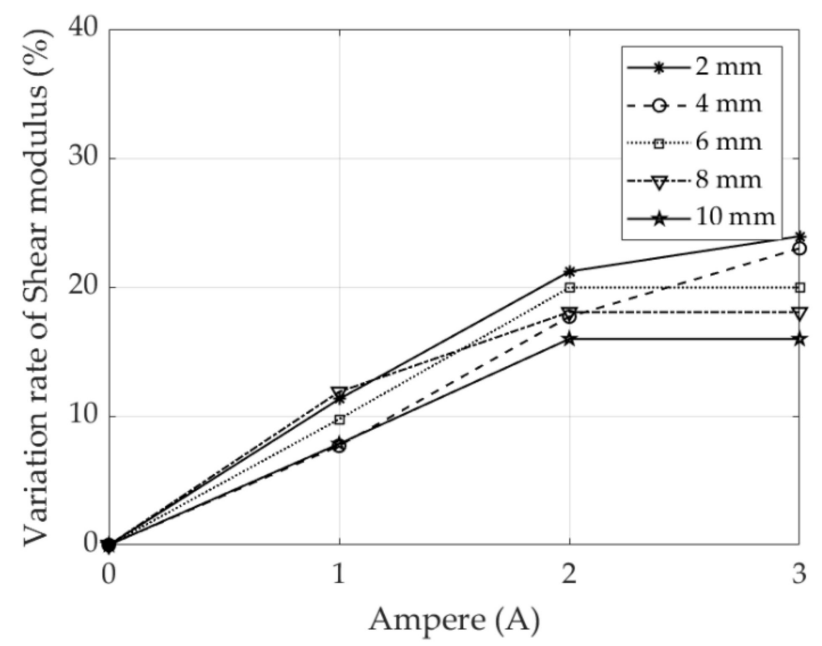

(a)

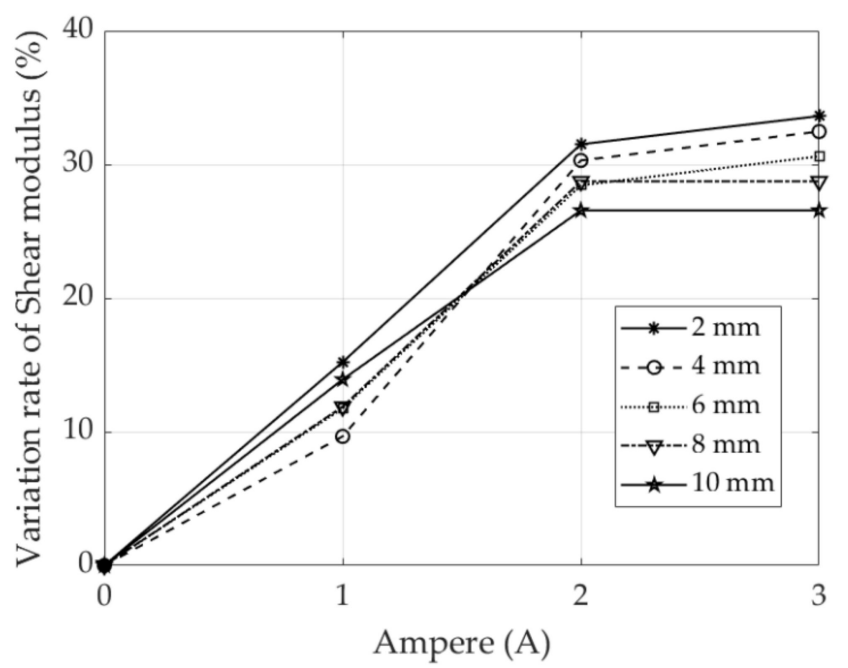

(b)

Figure 11. Variation rate of shear modulus isotropic/anisotropic MRE. (a) Isotropic MRE, (b) Anisotropic MRE.

\subsection{Derivation of Equations for the Magnetic Field and Mass of the MRE-Based ATDVA}

The shear modulus of MREs varies with the application of a magnetic field to the MRE-based ATDVA. For such shear modulus to be used as stiffness, the installation of MREs was designed to keep the plane of MRP vibration perpendicular to the direction of MRP orientation.

The overall structure of the MRE-based ATDVA is as follows (Figure 12):

The mass part of the MRE-based ATDVA is shown in Figure 13a. The mass part consisted of a coil and a core (Figure 13a). The MRE was made installable inside so that a magnetic field could flow through the MRE when applied to the coil, and a magnetic conductor was configured as a closed circuit for the flow of the magnetic field (Figure 13b). In addition, a joint was created for connection between the magnetic conductor and the mass part. The portion connected with the MRE was shaped to have a circular cross section so the flow of the magnetic field could be facilitated, and other magnetic conductors were formed into quadrangular shapes for the ease of fabrication.

Magnetic conductors were made of SC10, which is characterized by high permeability as one of the lowest-carbon steels for structural applications in mechanical parts. They were configured as closed circuits to maximize the performance of applying a magnetic field, and their edges were filleted for prevention of fringing flux. 


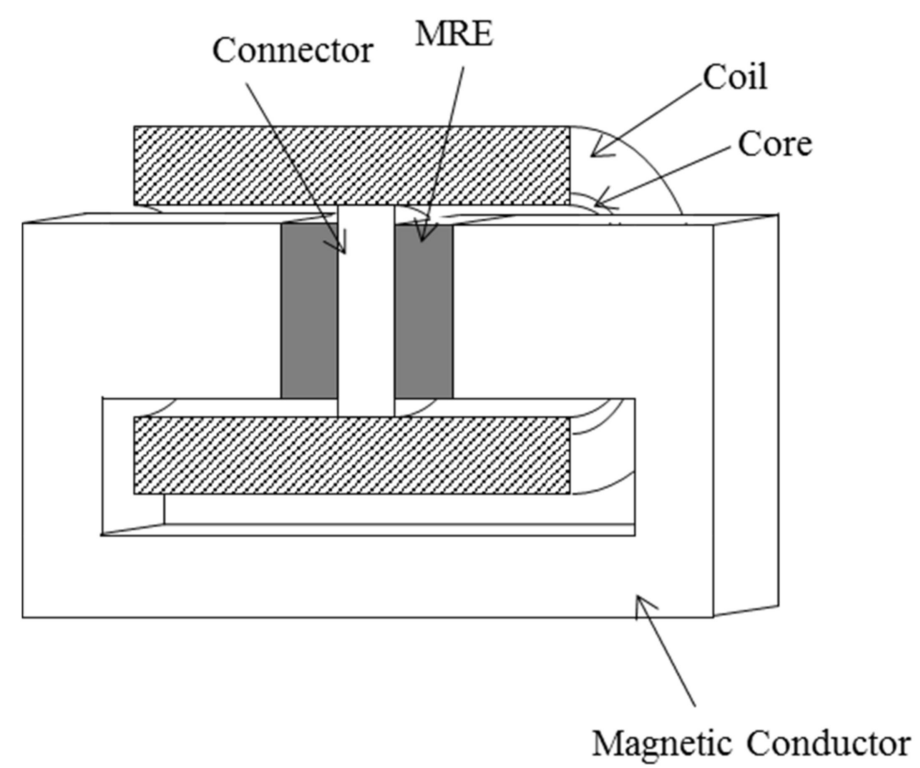

Figure 12. Cross sectional-view of adaptive tuned MRE vibration absorber.

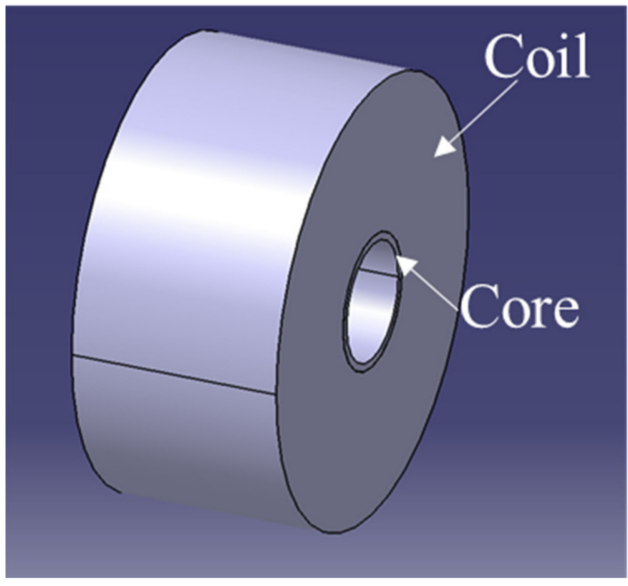

(a)

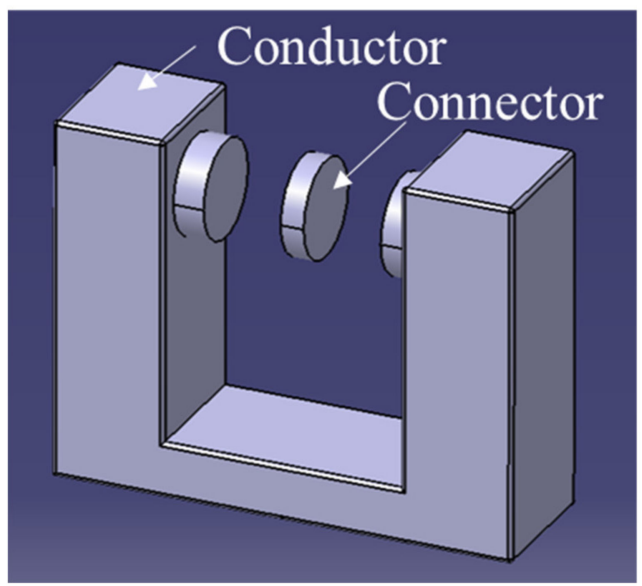

(b)

Figure 13. Components of adaptive tuned MRE vibration absorber. (a) coil part, (b) magnetic conductor and connector.

Non-magnetic brass was used for the core of the mass part. The joint between the mass part and magnetic conductor was made of the carbon steel SC10 as for the magnetic conductors.

The MRE was designed in a solenoid shape in combination with the coil so that it could be positioned in the center of the core where the magnetic field was strongest.

The materials used for the MRE-based ATDVA are listed in Table 3.

Table 3. Materials of ATMVA.

\begin{tabular}{cccc}
\hline Coil & Core & Connector & Magnetic Conductor \\
\hline Copper & Brass & SC10 & SC10 \\
\hline
\end{tabular}

The magnetic field strength for application to the MRE can be derived theoretically as follows:

Magnetomotive force is measured in ampere-turns (A-t) of coils and represents the force that produces a magnetic field in a magnetic circuit, as given by Equation (10) (Figure 14).

$$
F=N \cdot I
$$


where $F$ is the magnitude of magnetomotive force, which is expressed in ampere-turns (A-t); $N$ is the number of coil turns; and $I$ is the current (A) in the coil.

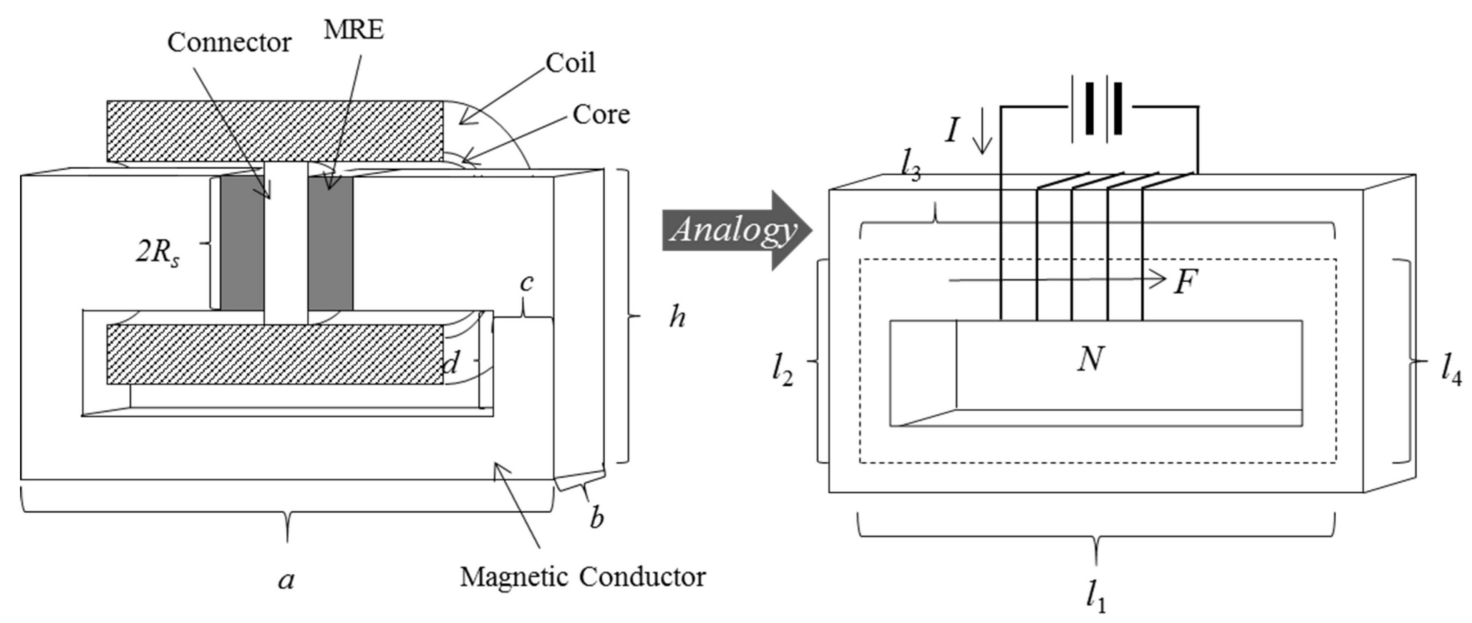

Figure 14. Magnetic circuit analogy model of adaptive tuned MRE vibration absorber.

The magnetic field strength is defined as the magnetomotive force per unit length in a magnetic field. The average magnetic field strength in the magnetic circuit section made up of homogeneous material is determined by dividing the magnetomotive force applied to the section by the section's effective length (1), as expressed by Equation (11).

$$
H=\frac{F}{l}=\frac{N \cdot I}{l}
$$

If the magnetic circuit has a uniform cross-sectional area, the magnetic field strength is equal throughout the magnetic circuit. If different cross-sectional areas or materials are used, the magnetic field strength varies from section to section.

In Figure 14, the respective sides of the core can be considered as serially connected magnetic resistances, so if they are defined as $l_{1}, l_{2}, l_{3}$ and $l_{4}$ in the clockwise direction from the side on which the coil is wound, the magnetic resistance of the core can be expressed as shown in equation (12).

$$
R_{e q}=\frac{l_{1}}{\mu \pi R_{S}^{2}}+\frac{2 l_{2}}{\mu b c}+\frac{l_{3}}{\mu b(h-d)}
$$

Therefore, the total magnetic flux passing through the magnetic circuit is given by Equation (13).

$$
\Phi_{e q}=\frac{N \cdot I}{R_{e q}}
$$

Because the MRE is positioned in the middle of the side for the coil to be wound on, the magnetic flux density $B_{1}$ is given by Equation (14).

$$
B_{1}=\frac{\Phi_{e q}}{A}=\frac{N \cdot I \cdot \mu b c(h-d)}{l_{1} b c(h-d)+2 l_{2} \pi R_{S}^{2}(h-d)+l_{3} \pi R_{S}^{2} c}
$$

The mass of the MRE-based ATDVA can be expressed as the sum of masses of the core and the coil wound on it, as given by the following equation:

$$
M=\pi R_{S}^{2} \times(a-2 c) \times \rho_{2}+\pi R_{C}^{2} \times L_{c} \times \rho_{C}
$$


where $R_{S}, L_{S}$ and $\rho_{S}$ represent the radius, length and density, respectively, of the core on which the coil is wound, and $R_{C}, L_{C}$ and $\rho_{c}$ are the radius, length and density, respectively, of the coil.

Because the coil wound on the core is multilayered, its length can be expressed as the product of the length of the wound coil per unit length and the number of layers. Figure 15 shows a cross-section of the core on which the coil is wound.

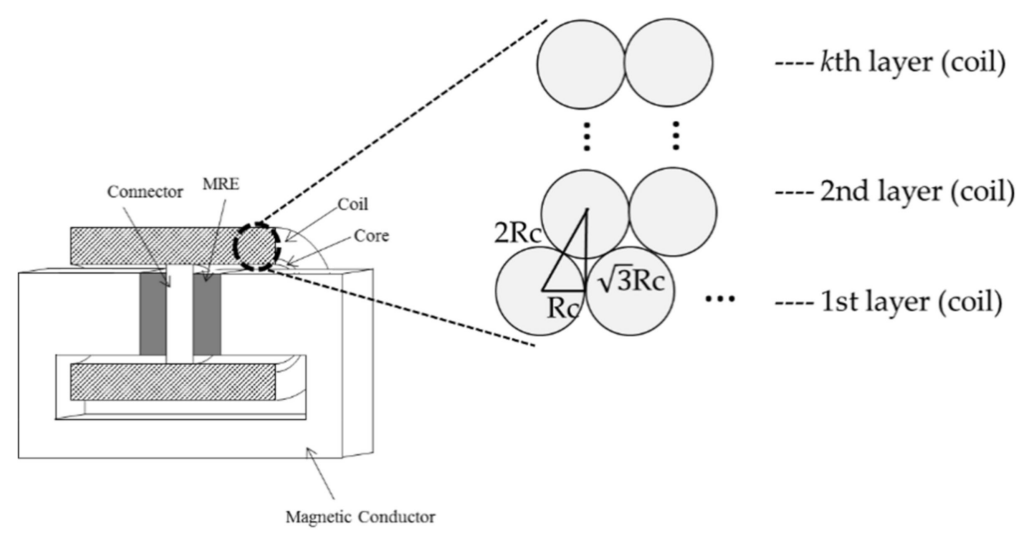

Figure 15. Cross section of coil part.

So $X_{k}$ corresponding to layer $k$ can be expressed as Equation (16).

$$
X_{k}=2\left\{R_{S}+(1+k \sqrt{3}) R_{C}\right\}
$$

The number of coil windings per unit length of the core is defined as a value divided by the diameter of the coil with a unit length of 1 .

The length $l_{k}$ of the coil wound on layer $k$ can be expressed as Equation (17).

$$
l_{k}=\frac{1}{2 R_{C}} \times 2 \pi\left\{R_{S}+R_{C}+(k-1) \sqrt{3} R_{C}\right\}
$$

Because the coil is wound over a length of $l_{k}$ from the first layer to layer $k$, the length of the wound coil per unit length is given by Equation (18).

$$
\begin{aligned}
& l_{c}=\sum_{n=1}^{k} \frac{1}{2 R_{C}} \times 2 \pi\left\{R_{S}+R_{C}+(k-1) \sqrt{3} R_{C}\right\} \\
& =k \pi \times \frac{1}{2 R_{C}} \times\left\{2 R_{S}+2 R_{C}+(k-1) \sqrt{3} R_{C}\right\}
\end{aligned}
$$

Consequently, the length of the coil wound on the core equals the product of $l_{c}$ and the coil winding length (a-2c), and substituting the values into Equation (15) yields Equation (19) for the mass of the MRE-based ATDVA.

$$
M=\pi R_{S}^{2} \times L_{S} \times \rho_{S}+l_{c} \times \pi R_{S}^{2} \times(a-2 c) \times \rho_{S}
$$

Therefore, optimization should be performed for the MRE-based ATDVA to have the mass determined by Equation (19) and maximize the magnetic field strength in Equation (14). In doing so, a genetic algorithm was used.

\subsection{Application of Sensitivity Analysis and Genetic Algorithms for Optimization of the MRE-Based ATDVA}

Genetic algorithms are based on the principle of biological evolution theory and genetics that individuals of superior quality tend to adapt well to the natural world and produce superior descendants. Because genetic algorithms have a group of individuals composed of binary combinations, they can 
provide a wide variety of cases when expressed in binary numbers and do not use gradients unlike conventional optimization algorithms.

In most cases, engineering optimization problems exhibit nonlinear behavior, and accordingly, gradient-based search techniques often reach local optimum points. In contrast, genetic algorithms are more likely to find global optimum points because they search the whole of a given design space without using gradients. A genetic algorithm involves the processes of propagation, selection, crossover and mutation. The propagation process generates a predetermined number (n) of design parameters. The value of $n$ representing the number of generated design parameters is converted into binary. The selection process determines how fit each individual is for the objective function and concludes that the higher the fitness of individuals, the more likely they are to influence their descendants. The basic idea of the roulette wheel model as the most widely used selection method is that individuals leave offspring in proportion to their fitness. The selection process finds the value of an objective function by substituting generated design parameters into the objective function. If the process is to find values of the design parameters that maximize the objective function, the selection probability for each design parameter is calculated by dividing the value of each design parameter by the sum of all function values. In addition, a cumulative probability is calculated for each design parameter. The cumulative probability is the sum of the first to kth selection probabilities. Each of the calculated cumulative probabilities is compared with a randomly generated number between 0 and 1 . If the first cumulative probability is greater than the first random number, the first design parameter is selected; likewise, if the kth cumulative probability is greater than the second random number, then the kth design parameter is selected. This process is repeated $\mathrm{m}$ times. As a result, $\mathrm{m}$ design parameters are selected after the selection process.

Subsequently, the crossover process selects random positions for random design parameters and crosses them over each other. The mutation process provides a global search effect by searching spaces other than the combination space of early genes by means of genetic modification occurring with a constant probability. Moderate mutations increase the rate of convergence towards the objective function and the diversity of groups. The mutations can be divided into two classes: static and dynamic. Static mutations take place with fixed mutation probabilities, whereas the probability of dynamic mutation varies from time to time. Typically, the mutations occur with a probability of $0.5-1$ per bit. The mutation process is a process wherein the binary value of 0 or 1 for a random position is converted into 1 or 0 .

If the genetic algorithm fails to reach a predetermined number of repeats, design parameters are propagated again and in turn undergo the processes of selection, crossover and mutation. Once the predetermined number of repeats is finally reached, the algorithm finds the values of design parameters that maximize the objective function. It is necessary to perform a sensitivity analysis for selecting design parameters of the MRE-based ATDVA. The sensitivity analysis was conducted for each of the design parameters in equation (14) as a formula for the magnetic field of the MRE-based ATDVA's mass part (Figure 16).

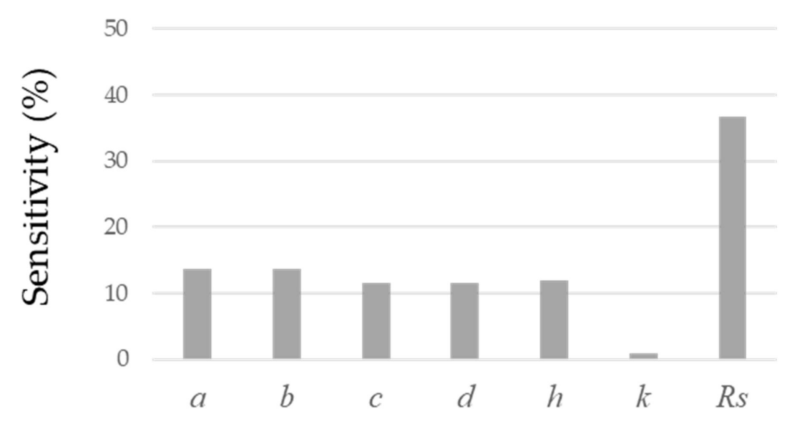

Design parameters

Figure 16. Design parameter sensitivity analysis of adaptive tuned MRE vibration absorber. 
The sensitivity analysis revealed that the sensitivity of design parameters was lowest for $k$ (which was removed for that reason), highest for $R_{S}$ and similar for $a, b, c, d$ and $h$; accordingly, the selected design parameters included $a, b, c, d, h$ and $R_{S}$. Before determination of the design parameter $k$, the mass of the dynamic vibration absorber was determined based on the lowest frequency of $110 \mathrm{~Hz}$ in the target range for vibration reduction and the MRE's stiffness at the time of $0 \mathrm{~A}$ application. The reason was that the MRE-based ATDVA would work to reduce the vibration at $110 \mathrm{~Hz}$ under the excitation of 0 A application, and the frequency for vibration reduction would increase with increasing MRE stiffness with the application of a current. Therefore, the MRE stiffness at the time of 0 A application and the lowest frequency of $110 \mathrm{~Hz}$ in the target range for vibration reduction were substituted into Equation (20) to determine the mass of the dynamic vibration absorber.

$$
k=(2 \mu f)^{2} m
$$

The mass calculated from Equation (20) was $1.55 \mathrm{~kg}$, and design parameters $a, b, c, d, h$ and $R_{S}$ were calculated using the genetic algorithm. The value of $k$ was determined by substituting the values of the design parameters into Equation (19), which represents a mass boundary condition of the MRE-based ATDVA.

For the application of seven design parameters in Table 4 to the genetic algorithm, the parameters are binarized into the boundary conditions for Equation (19) and then expressed as a matrix. This is what we call the propagation process. The subsequent selection process calculates the magnetic field strength using Equation (14) and the probability of selection from the magnetic field strength. Genes with high selection probability are selected and left behind.

This selection procedure is called roulette wheel selection. The crossover process determines crossover points randomly using a simple crossover to accelerate the rate of convergence and allows different genes to cross over at the random points. Finally, the mutation process mutates genes with a $1 \%$ probability for a global search effect.

Through the processes described above, the genetic algorithm finds optimal design parameters for the MRE-based ATDVA to have a maximum magnetic field strength.

For size constraints, $R_{S}$ was set to be no larger than the MRE $\left(R_{S} \leq 15 \mathrm{~mm}\right)$ for a combination with the coil, and $\mathrm{d}$ was larger than the radius $(>52.5 \mathrm{~mm})$ of the coil. Because parameters $b$ and $c$ determine the cross-sectional areas of both magnetic paths, the larger their size, the greater the magnetic resistance. Therefore, the lower values are more favorable. The value of $b$ was set to the smallest whole number larger than $R_{S}$ because it influences the cross-sectional area of the lower magnetic path as well. The value of $h$ was set to be greater than the coil's radius $(h>52.5 \mathrm{~mm})$.

Table 4 lists the parameters necessary for optimization and their optimized values.

Table 4. Initial and optimized value of design parameters.

\begin{tabular}{ccc}
\hline Design Parameters & Initial Value & Optimized Value \\
\hline$a$ & $120 \mathrm{~mm}$ & $120 \mathrm{~mm}$ \\
$b$ & $37 \mathrm{~mm}$ & $37 \mathrm{~mm}$ \\
$c$ & $29 \mathrm{~mm}$ & $29 \mathrm{~mm}$ \\
$d$ & $52.5 \mathrm{~mm}$ & $80.5 \mathrm{~mm}$ \\
$h$ & $52.5 \mathrm{~mm}$ & $95 \mathrm{~mm}$ \\
$k$ & 280 layer & 300 layer \\
$R_{s}$ & $10 \mathrm{~mm}$ & $13 \mathrm{~mm}$ \\
\hline
\end{tabular}

The optimization results showed that the magnetic field strength improved from $20.45 \mathrm{mT}$ to $30.35 \mathrm{mT}$ with $a=120 \mathrm{~mm}, b=37 \mathrm{~mm}, c=29 \mathrm{~mm}, d=80.5 \mathrm{~mm}, h=95 \mathrm{~mm}, k=300$ layers and $R_{s}=$ $13 \mathrm{~mm}$. The final configuration is shown in Figure 17. 


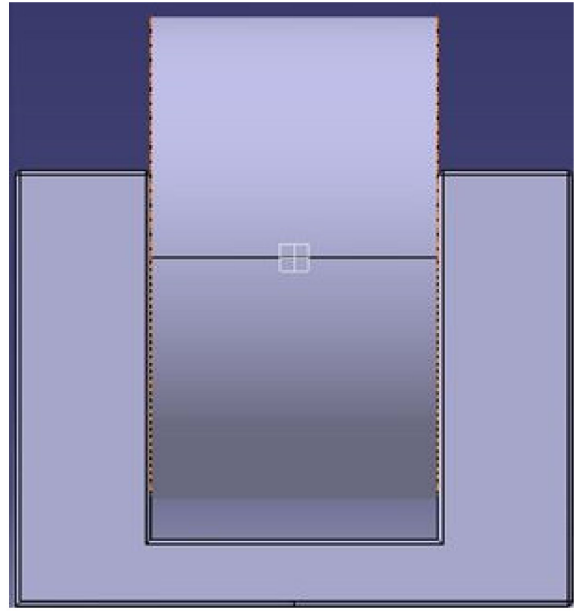

(a)

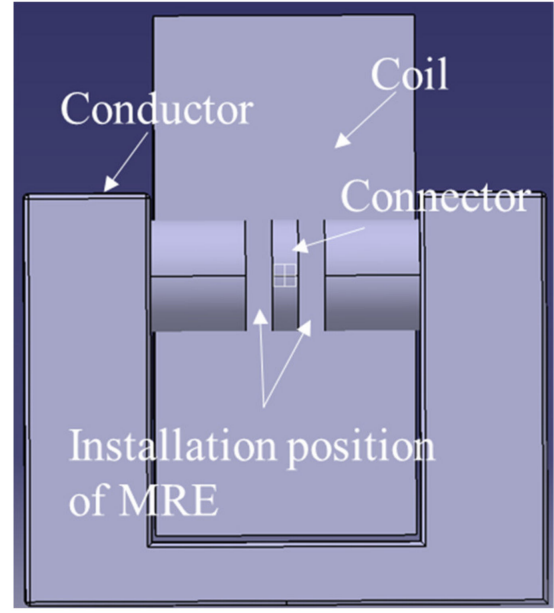

(b)

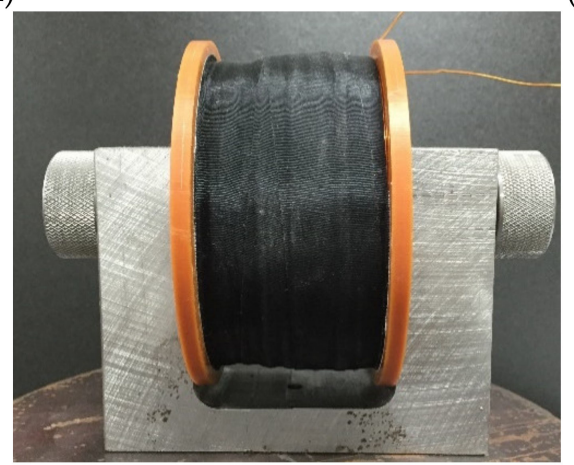

(c)

Figure 17. Optimized model of adaptive tuned MRE vibration absorber. (a) CAD model, (b) cross sectional view, (c) prototype.

\section{Vibration Reduction by the MRE-Based ATDVA under Variable-Frequency Excitation}

\subsection{Experimental Setup and Methods}

The MRE-based ATDVA works to reduce vibrations with variable frequencies excited. An electric current should be applied under the condition of frequency excitation so that the MRE stiffness is variable. Accordingly, this study describes the process of applying a current to the MRE-based ATDVA to detect and reduce the variable frequencies in real time.

The short-time Fourier transform (STFT) of acceleration responses was performed to detect the frequency applied to a plane plate at the time of variable-frequency excitation.

The frequency resolution was set to $1 \mathrm{~Hz}$ with a sampling rate of $0.004 \mathrm{~s}$ and an FFT block size of 128. If any peak excitation frequency is detected in a frequency range targeted for vibration reduction, an electric current is applied based on relationships between the peak frequency and the stiffness of the MRE-based ATDVA and between the MRE-based ATDVA and the vibration reduction frequency. If the current is applied depending on the excitation frequency, the MRE-based ATDVA can reduce vibrations in real time. As shown in Figure 18, an experimental setup was built to evaluate the performance of the MRE-based ATDVA.

In this work, we used a function generator (SEINTEK G5100) for variable-frequency excitation and a power amplifier (Inkel MA 320) for signal amplification. For the frequency excitation, a plate was to be excited in its center. The adaptive tuned MRE-based ATDVA was placed in the center of the plate where displacement was greatest. Likewise, an accelerator (Endevco 65-100-X) was installed in the center where the greatest displacement occurred.

The MRE-based ATDVA reduces vibrations at a variable frequency by applying an electric current to match the frequency. LabVIEW Compact-Rio 9204 was therefore used to measure frequencies under 
the condition of variable-frequency excitation and apply a current accordingly. Because LabVIEW's current application module (NI9265) allowed for the application of up to $0.02 \mathrm{~A}$, an amplifier circuit as shown in Figure 19 was fabricated to amplify the current to 3 A.

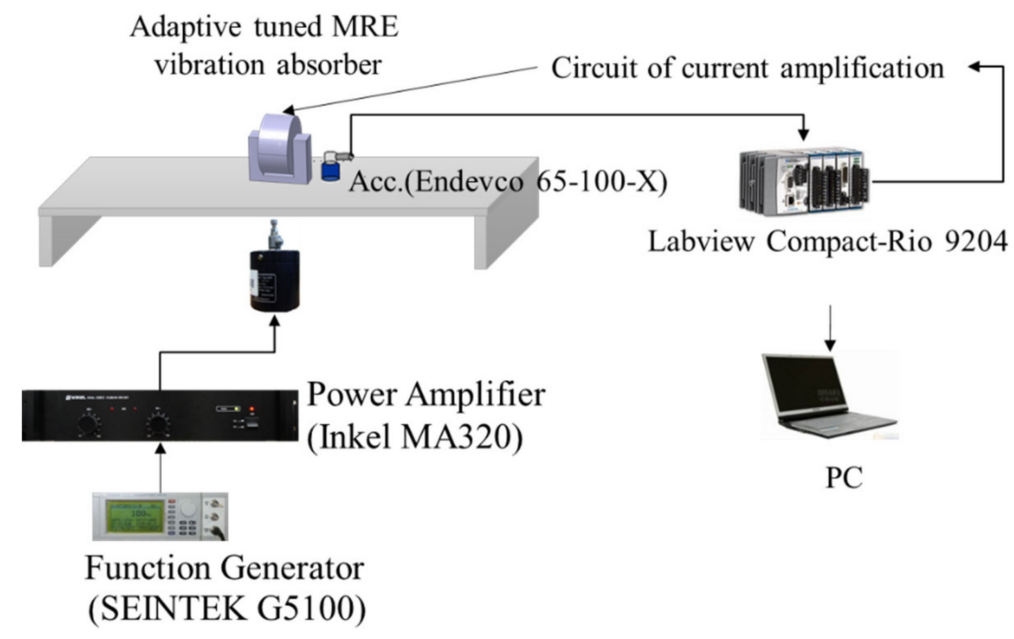

Figure 18. Experimental setup.

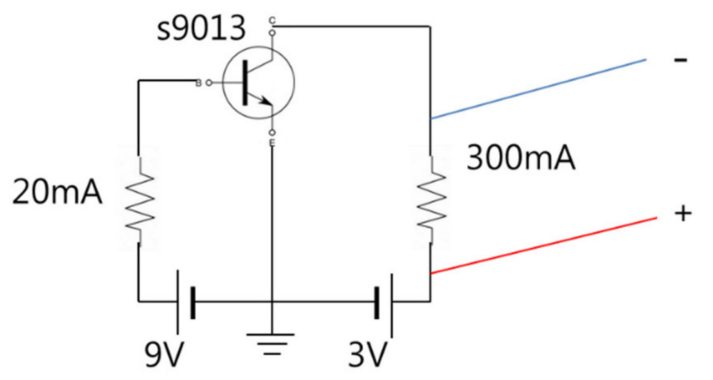

Figure 19. Circuit of current amplification.

When attached, the current amplifier circuit in Figure 19 achieved a current amplification of 0.3 A for each channel of LabVIEW's current application module. Consequently, a current of 3 A was obtained when the connection of the circuit was extended to ten channels.

\subsection{Building a Current-Frequency Relationship for Stiffness Control}

The MRE-based ATDVA works to reduce vibrations with variable frequencies excited. An electric current should be applied under the condition of frequency excitation so that the MRE's stiffness is variable. Accordingly, the stiffness relationship of the MRE-based ATDVA and the relationship between its stiffness and vibration reduction frequency must be identified experimentally for the real-time detection and reduction of variable frequencies. Further, there is a need to build the relationship between the applied current and the ATDVA's vibration reduction frequency.

In identifying the relationship between the variable excitation frequency and the stiffness of the MRE-based ATDVA, the shear modulus measuring system proposed by Yoon et al. was used to measure the stiffness of MREs with the application of electric current at intervals of $0.5 \mathrm{~A}$ from $0 \mathrm{~A}$ to $3 \mathrm{~A}$. The MREs presented in chapter 3 were used as MRE specimens. Figure 18 shows a diagram of the experimental setup. The shear modulus of each MRE was measured with $0-20 \mathrm{kHz}$ white noise as excitation. Given as Equation (21), the equilibrium equation of force for the MRE's shear strain was derived from the shear modulus measurements (Figure 20).

$$
G_{M R E}=k_{\tau}^{*} h
$$

Likewise, the stiffness of MREs was measured at intervals of $0.5 \mathrm{~A}$ from $0 \mathrm{~A}$ to $3 \mathrm{~A}$ (Table 5). 


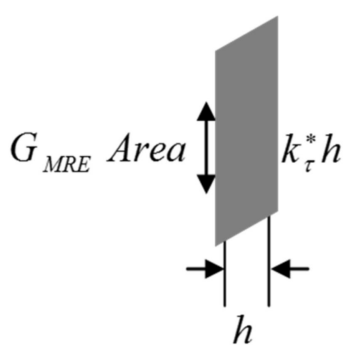

Figure 20. Shear deformation of magnetorheological elastomer.

Table 5. Stiffness measurement of magnetorheological elastomer due to current.

\begin{tabular}{ccc}
\hline Current (A) & Stiffness $\mathbf{( k N / m )}$ & Target Frequency $\mathbf{( H z )}$ \\
\hline 0.0 & 375.2 & 110 \\
0.5 & 389.1 & 116 \\
1.0 & 439.8 & 121 \\
1.5 & 470.1 & 125 \\
2.0 & 477.8 & 129 \\
2.5 & 481.4 & 130 \\
3.0 & 485.6 & 131 \\
\hline
\end{tabular}

The correlation between vibration reduction frequency and stiffness was determined using the mass and stiffness of the MRE-based ATDVA.

Figure 21 shows how the vibration reduction frequency varied with the applied electric current. As seen in the figure, the vibration reduction frequency increased with the application of electric current and varied significantly with rapidly changing MRE stiffness between $0 \mathrm{~A}$ and $2 \mathrm{~A}$. The vibration reduction frequencies between the currents applied at 0.5-A intervals were estimated using a linear interpolation.

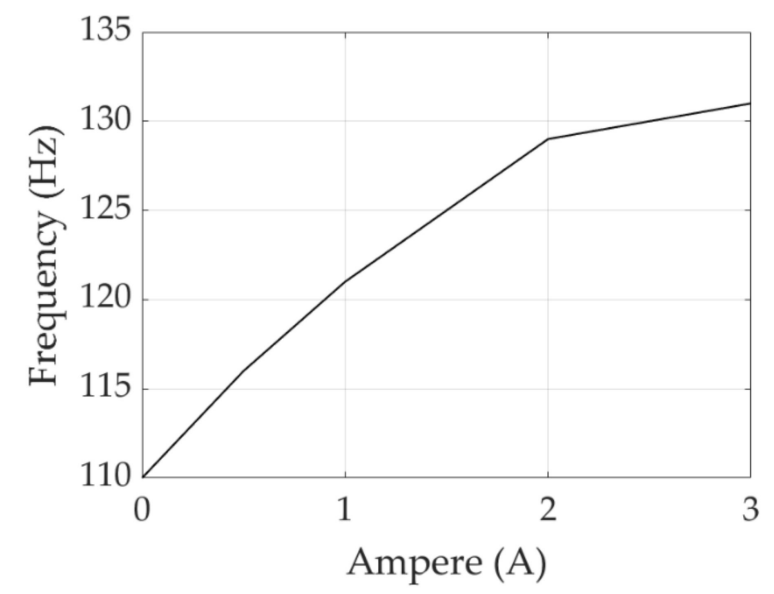

Figure 21. Reduction frequency of ATMVA due to induced current.

\subsection{Vibration Reduction by the MRE-Based ATDVA under Variable-Frequency Excitation}

The vibration-reducing performance of the MRE-based ATDVA was evaluated under the condition of variable-frequency excitation. We applied currents of $0 \mathrm{~A}, 1 \mathrm{~A}, 2 \mathrm{~A}$ and $3 \mathrm{~A}$ and evaluated the variable performance of vibration reduction under the condition of each current application (see Figure 22).

The vibration reduction frequency range increased with increasing magnitude of the applied current. The ATDVA reduced vibrations in frequency ranges near $110 \mathrm{~Hz}$ at $0 \mathrm{~A}, 122 \mathrm{~Hz}$ at $1 \mathrm{~A}, 128 \mathrm{~Hz}$ at $2 \mathrm{~A}$, and $130 \mathrm{~Hz}$ at $3 \mathrm{~A}$. These findings are consistent with the data presented in Table 5 and indicate that the ATDVA's vibration-reducing performance depended on the applied current.

The control algorithm presented was used to evaluate the vibration-reducing performance of the MRE-based ATDVA at the time of variable-frequency excitation (see Figure 23). 


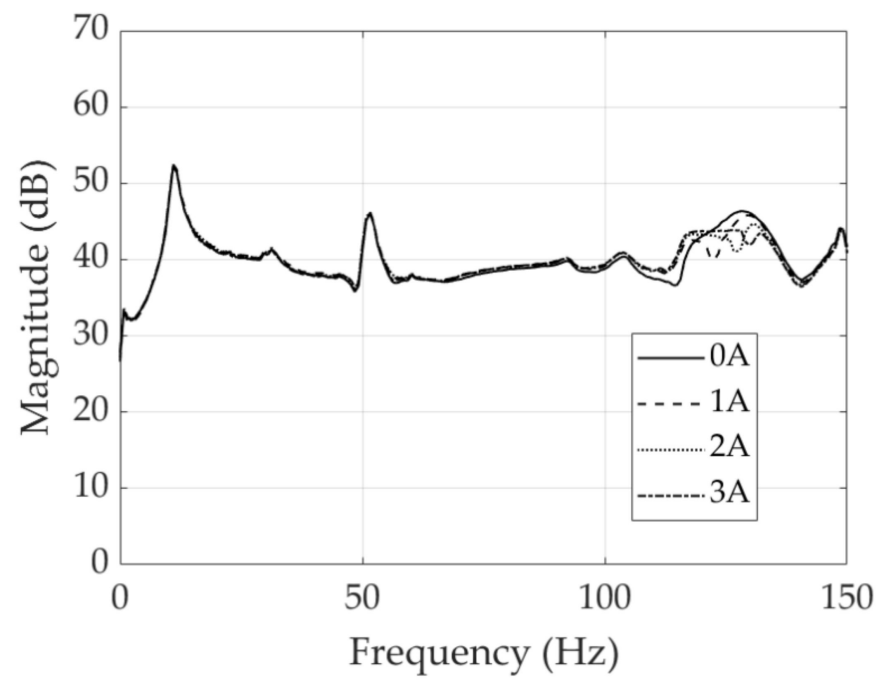

Figure 22. Vibration reduction results of adaptive tuned MRE vibration absorber by frequency-variable excitation [current: $0,1,2,3 \mathrm{~A}$ ].

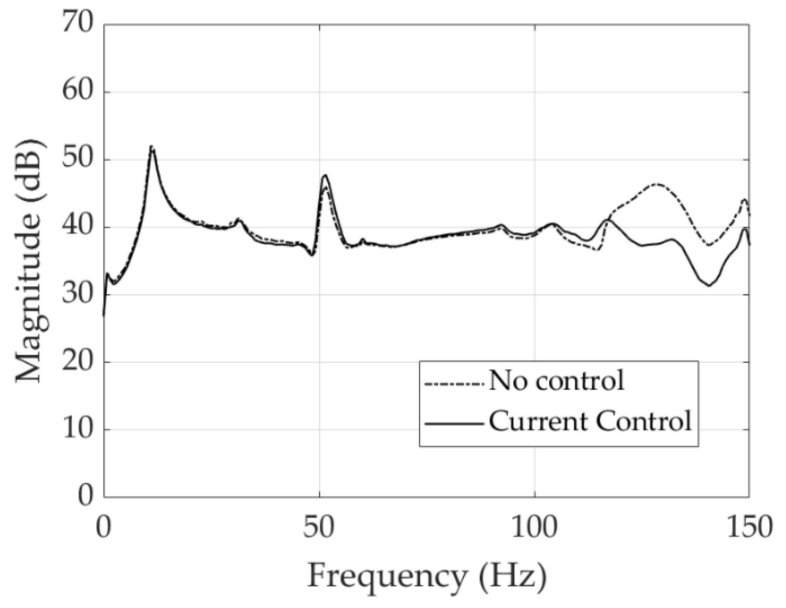

(a)

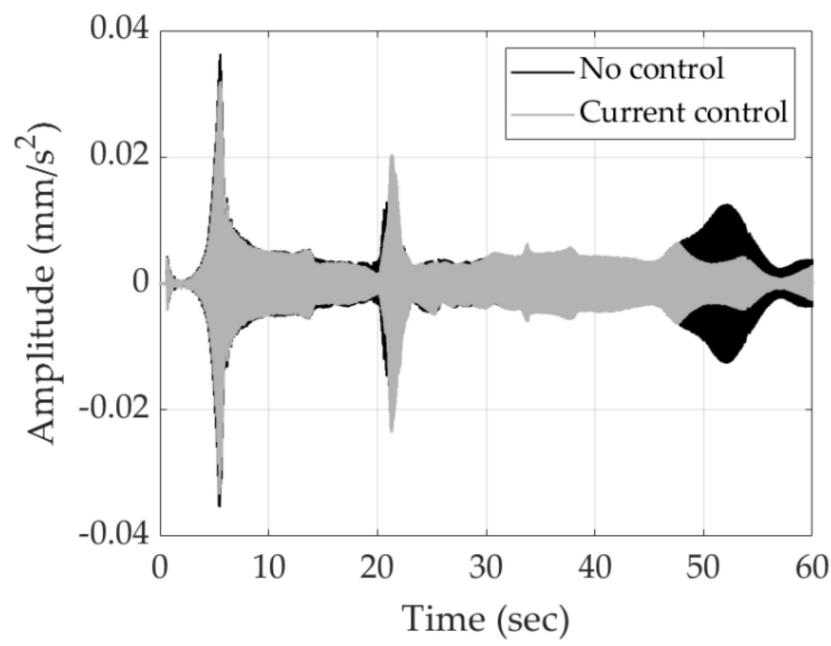

(b)

Figure 23. Vibration reduction results of adaptive tuned MRE vibration absorber by frequency-variable excitation. (a) Frequency response function, (b) Time response. 
The MRE-based ATDVA achieved a vibration reduction of $8.38 \mathrm{~dB}$ in the designed target frequency range of $110-130 \mathrm{~Hz}$ (Figure 23a). In the time domain, it was found to reduce vibrations in a range of 47-53 s (Figure 23b).

There was no significant difference between frequency characteristics when the MRE-based ATDVA was not installed and those in ranges other than the target frequency range for vibration reduction when the ATDVA was installed (Figure 23a). This suggests that unlike SDOF or dual dynamic vibration absorbers, the MRE-based ATDVA when installed produces no resonance frequency in a target object for vibration reduction under variable-frequency excitation. The phenomenon called resonance occurs if the excitation frequency at the time of variable-frequency excitation happens to match the resonance frequency of the target object for vibration reduction. Under the condition of variable-frequency excitation, therefore, superior vibration reduction is achieved by installing an MRE-based ATDVA rather than an SDOF or dual dynamic vibration absorber.

\section{Conclusions}

In this study, we designed an MRE-based ATDVA that reduces vibrations at the time of variable-frequency excitation and evaluated its vibration-reducing performance. Based on the findings, we have come to the following conclusions:

(1) The adaptive tuned dynamic vibration absorber exhibited superior performance of vibration reduction to SDOF and dual dynamic vibration absorbers at target frequencies under the condition of variable-frequency excitation.

(2) We identified the natural frequencies of a plane plate as the target object for vibration reduction. MREs were designed for application to the MRE-based ATDVA. In addition, the mass and magnetic field of the MRE-based ATDVA's mass part were theoretically formulated, and design optimization was performed using a sensitivity analysis and genetic algorithm.

(3) This study attempted to determine how the vibration reduction frequencies of the MRE-based ATDVA are related to the electric currents applied to the dynamic vibration absorber. Our evaluation of the MRE-based ATDVA's vibration-reducing performance under the condition of variable-frequency excitation found that vibrations were reduced in target frequency ranges.

Funding: This research received no external funding.

Conflicts of Interest: The author declares no conflict of interest.

\section{References}

1. Den Hartog, J.P. Mechanical Vibrations, 4th ed.; Courier Dover Publications: New York, NY, USA, 1985; pp. 112-119.

2. Inman, D.J. Engineering Vibration, 4th ed.; Pearson: New York, NY, USA, 2014; pp. 455-462.

3. Ormondroyd, J.; den Hartog, J.P. The theory of the dynamic vibration absorber. ASME J. Appl. Mech. 1928, $50,9-22$.

4. Bekdaş, G.; Nigdeli, S.M. Mass ratio factor for optimum tuned mass damper strategies. Int. J. Mech. Sci. 2013, 71, 68-84. [CrossRef]

5. Cheung, Y.; Wong, W.O. H $\infty$ and $\mathrm{H} 2$ optimizations of a dynamic vibration absorber for suppressing vibrations in plates. J. Sound Vib. 2009, 320, 29-42. [CrossRef]

6. Miguélez, M.; Rubio, M.L.; Loya, J.; Fernández-Sáez, J. Improvement of chatter stability in boring operations with passive vibration absorbers. Int. J. Mech. Sci. 2010, 52, 1376-1384. [CrossRef]

7. Iwanami, K.; Seto, K. An Optimum Design Method for the Dual Dynamic Damper and its Effectiveness. Bull. JSME 1984, 27, 1965-1973. [CrossRef]

8. Yamaguchi, H.; Harnpornchai, N. Fundamental characteristics of Multiple Tuned Mass Dampers for suppressing harmonically forced oscillations. Earthq. Eng. Struct. Dyn. 1993, 22, 51-62. [CrossRef]

9. Franchek, M.; Ryan, M.; Bernhard, R. Adaptive passive vibration control. J. Sound Vib. 1996, 189, 565-585. [CrossRef] 
10. Rogers, C.; Liang, C.; Jia, J. Behavior of shape memory alloy reinforced composite plates. I-Model formulations and control concepts. 30th Struct. Struct. Dyn. Mater. Conf. 1989, 89, 2011-2017. [CrossRef]

11. Rustighi, E.; Brennan, M.J.; Mace, B.R. Real-time control of a shape memory alloy adaptive tuned vibration absorber. Smart Mater. Struct. 2005, 14, 1184-1195. [CrossRef]

12. Williams, K.; Chiu, G.T.-C.; Bernhard, R. Adaptive-passive absorbers using shape-memory alloys. J. Sound Vib. 2002, 249, 835-848. [CrossRef]

13. Tiseo, B.; Concilio, A.; Ameduri, S.; Gianvito, A. A shape memory alloys based tuneable dynamic vibration absorber for vibration tonal control. J. Theor. Appl. Mech. 2010, 48, 135-153.

14. Savi, M.A.; De Paula, A.S.; Lagoudas, D. Numerical Investigation of an Adaptive Vibration Absorber Using Shape Memory Alloys. J. Intell. Mater. Syst. Struct. 2010, 22, 67-80. [CrossRef]

15. Lee, C.-Y.; Chen, C.-C.; Yang, T.-H.; Lin, C.-J. Structural vibration control using a tunable hybrid shape memory material vibration absorber. J. Intell. Mater. Syst. Struct. 2012, 23, 1725-1734. [CrossRef]

16. Fosdick, R.; Ketema, Y. A Thermoviscoelastic Dynamic Vibration Absorber. J. Appl. Mech. 1998, 65, 17-24. [CrossRef]

17. Ketema, Y. A Viscoelastic dynamic vibration absorber with adaptable suppression band: A feasibility study. J. Sound Vib. 1998, 216, 133-145. [CrossRef]

18. Faidley, L.E.; Dapino, M.J.; Washington, G.N.; Lograsso, T.A. Modulus Increase with Magnetic Field in Ferromagnetic Shape Memory Ni-Mn-Ga. J. Intell. Mater. Syst. Struct. 2006, 17, 123-131. [CrossRef]

19. Sarawate, N.N.; Dapino, M.J. Stiffness Tuning with Bias Magnetic Fields in Ferromagnetic Shape Memory Ni-Mn-Ga. J. Intell. Mater. Syst. Struct. 2009, 20, 1625-1634. [CrossRef]

20. Deng, H.; Gong, X. Application of magnetorheological elastomer to vibration absorber. Commun. Nonlinear Sci. Numer. Simul. 2008, 13, 1938-1947. [CrossRef]

21. Yoon, J.-H.; Yang, I.-H.; Jeong, U.-C.; Chung, K.; Lee, J.-Y.; Oh, J.-E. Investigation on variable shear modulus of magnetorheological elastomer based on natural rubber due to change of fabrication design. Polym. Eng. Sci. 2012, 53, 992-1000. [CrossRef]

22. Chung, K.; Jeong, U.; Oh, J.-E. Effects of magnetic field input cycle and peptizer on the MR effect of magneto-rheological elastomer based on natural rubber. Polym. Eng. Sci. 2015, 55, 2669-2675. [CrossRef]

23. Du, G.; Huang, X.; Li, Y.; Ouyang, Q.; Wang, J. Performance of a semi-active/passive integrated isolator based on a magnetorheological elastomer and spring. Smart Mater. Struct. 2017, 26, 095024. [CrossRef]

24. Kaleta, J.; Królewicz, M.; Lewandowski, D. Magnetomechanical properties of anisotropic and isotropic magnetorheological composites with thermoplastic elastomer matrices. Smart Mater. Struct. 2011, 20, 85006. [CrossRef]

25. Gong, X.; Zhang, X.; Zhang, P. Fabrication and characterization of isotropic magnetorheological elastomers. Polym. Test. 2005, 24, 669-676. [CrossRef]

26. Schrittesser, B.; Major, Z.; Filipcsei, G. Characterization of the dynamic mechanical behavior of magnetoelastomers. J. Phys. 2009, 149, 012096. [CrossRef]

27. Alberdi-Muniain, A.; Gil-Negrete, N.; Kari, L. Influence of carbon black and plasticisers on dynamic properties of isotropic magnetosensitive natural rubber. Plast. Rubber Compos. 2012, 41, 310-317. [CrossRef]

28. Kruželák, J.; Hudec, I.; Dosoudil, R. Elastomeric magnetic composites-Physical properties and network structure. Polimery 2012, 57, 25-32. [CrossRef]

29. Zhang, W.; Gong, X.; Xuan, S.; Jiang, W. Temperature-Dependent Mechanical Properties and Model of Magnetorheological Elastomers. Ind. Eng. Chem. Res. 2011, 50, 6704-6712. [CrossRef]

30. Chen, L.; Gong, X.-L.; Jiang, W.-Q.; Yao, J.-J.; Deng, H.; Li, W. Investigation on magnetorheological elastomers based on natural rubber. J. Mater. Sci. 2007, 42, 5483-5489. [CrossRef]

31. Lei, C.; Li, S.-L.; Xu, R.-J.; Xu, Y.-Q. Thermoplastic vulcanizates based on compatibilized polyurethane and silicone rubber blend. J. Elastomers Plast. 2012, 44, 563-574. [CrossRef]

32. Balasoiu, M.; Lebedev, V.T.; Orlova, D.N.; Bica, I. Magnetic field and particle concentration competitive effects on ferrofluid based silicone elastomer microsturucture. Critallography Rep. 2011, 56, 1177-1180. [CrossRef]

33. You, H.; Bai, Q.; Liu, Y.C.; Ning, L.W. Preparation and Mechanics Properties of MR Elastomers Based on Silicone Rubber. Appl. Mech. Mater. 2010, 34, 942-945. [CrossRef]

34. Von Lockette, P.R.; Lofland, S.; Koo, J.-H.; Kadlowec, J.; Dermond, M. Dynamic characterization of bimodal particle mixtures in silicone rubber magnetorheological materials. Polym. Test. 2008, 27, 931-935. [CrossRef] 
35. Böse, H. Viscoelastic properties of silicone-based magnetorheological elastomers. Int. J. Mod. Phys. B 2007, 21, 4790-4797. [CrossRef]

36. Kallio, M.; Lindroos, T.; Aalto, S.; Järvinen, E.; Kärnä, T.; Meinander, T. Dynamic compression testing of a tunable spring element consisting of a magnetorheological elastomer. Smart Mater. Struct. 2007, 16, 506-514. [CrossRef]

37. Li, J.F.; Gong, X.L.; Zhang, X.Z.; Zhang, P.Q. Research on magnetorheological elastomer based on silicone rubber. J. Funct. Mater. 2006, 37, 1005-1012.

38. Kallio, M. The elastic and damping properties of magnetorheological elastomers. VTT Publ. 2005, 585, 146.

39. Gong, X.; Wang, Y.; Gong, X.; Zhang, X.; Jiang, W.; Zhang, P.; Chen, Z.; Gong, X. New magnetorheological elastomers based on polyurethane/Si-rubber hybrid. Polym. Test. 2005, 24, 324-329. [CrossRef]

40. Hu, Y.; Wang, Y.L.; Gong, X.Q.; Gong, X.L.; Zhang, X.Z.; Jiang, W.Q.; Zhang, P.Q.; Chen, Z.Y. Magnetorheological elastomers based on polyurethane/si-rubber hybrid. Int. J. Mod. Phys. B 2005, 19, 1114-1120. [CrossRef]

41. Zhang, X.; Peng, S.; Wen, W.; Li, W. Analysis and fabrication of patterned magnetorheological elastomers. Smart Mater. Struct. 2008, 17, 45001. [CrossRef]

42. Minagawa, K.; Koyama, K. Electro- and Magneto-Rheological Materials: Stimuli-Induced Rheological Functions. Curr. Org. Chem. 2005, 9, 1643-1663. [CrossRef]

43. Malik, A.; Zhang, Z.; Agarwal, R.K. Extraction of battery parameters using a multi-objective genetic algorithm with a non-linear circuit model. J. Power Sources 2014, 259, 76-86. [CrossRef]

44. Kucharzyk, K.H.; Crawford, R.; Paszczyński, A.; Soule, T.; Hess, T.F. Maximizing microbial degradation of perchlorate using a genetic algorithm: Media optimization. J. Biotechnol. 2012, 157, 189-197. [CrossRef]

(C) 2020 by the author. Licensee MDPI, Basel, Switzerland. This article is an open access article distributed under the terms and conditions of the Creative Commons Attribution (CC BY) license (http://creativecommons.org/licenses/by/4.0/). 